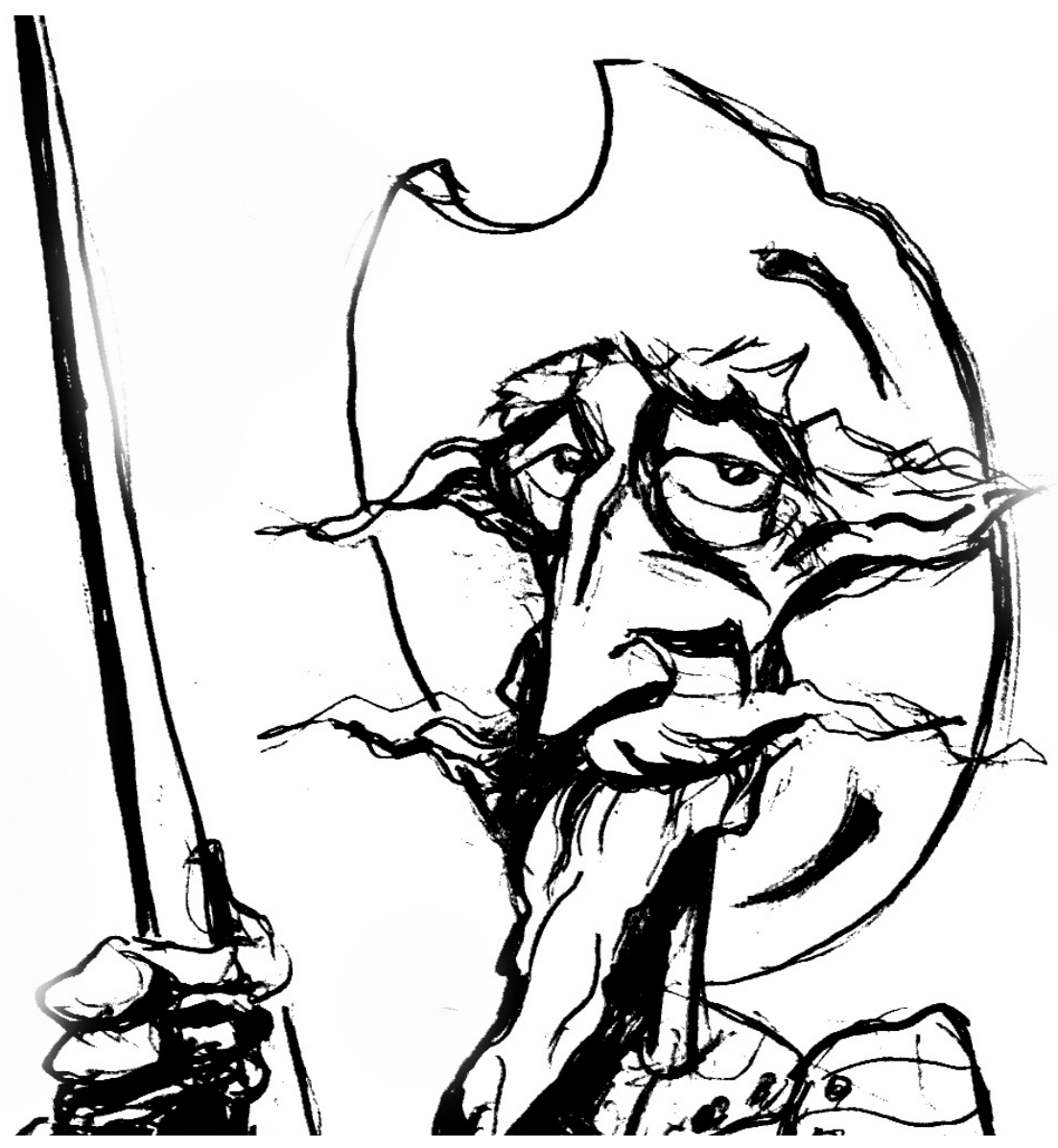

Malvinas y el mundo: registros portuarios históricos de las islas (1826-1832 y 1842-1914)

[Sofía Clara Haller] 



\title{
Malvinas y el mundo: registros portuarios históricos de las islas (1826-1832 y 1842-1914)*
}

\section{Malvinas and the World: Historical Shipping Registers of the Islands (1826- 1832 and 1842-1914)}

\author{
SOFÍA CLARA HALLER
}

\section{Resumen}

Los registros históricos de entradas y salidas de navíos de la costa malvinense permiten explorar las conexiones navieras del archipiélago entre 1826 y 1914. La reconstrucción de dichas conexiones integrada con información heterogénea proveniente de distintos repositorios documentales y de bases de datos de viajes históricos, hace posible visibilizar las actividades y necesidades que convocaban a los barcos a las islas Malvinas, los distintos actores que formaron parte de su historia, el cambio de las relaciones marítimas de las islas antes y después de la ocupación británica de 1833 y las conexiones internacionales del archipiélago con puntos de la Patagonia continental y el estrecho de Magallanes.

\section{Palabras clave}

Malvinas; Historia Marítima; Puerto; Patagonia; Loberos

\begin{abstract}
The historical shipping records of the Malvinas Islands coasts allow us to explore the maritime connections that the archipelago had between 1826 and 1914. The reconstruction of such connections, integrated with heterogeneous information from different archives and databases of historical voyages, makes it possible to identify the activities and needs that brought ships to the Malvinas Islands, the different actors that were part of their history, the change in the maritime relation before and after the British occupation of 1833, and the international connections of the archipelago with different points in continental Patagonia and the strait of Magellan.
\end{abstract}

\section{Keywords}

Malvinas; Maritime History; Port; Patagonia; Sealers

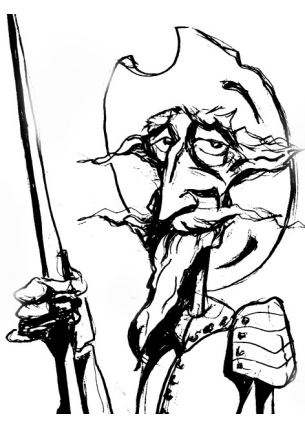

Recibido con pedido de publicación el 2 de marzo de 2020

Aceptado para su publicación el 3 de junio de 2020

Versión definitiva recibida el 12 de julio de 2020

Sofía Clara Haller, Instituto Patagónico de Ciencias Sociales y Humanas, Centro Nacional Patagónico, Consejo Nacional de Investigaciones Científicas y Técnicas, Puerto Madryn, Argentina; e-mail: hallersc@gmail.com

\footnotetext{
* Agradezco a Federico Lorenz por sus sugerencias. Asimismo, agradezco los comentarios recibidos por parte de los árbitros anónimos de la revista.

Esta obra se publica bajo licencia Creative Commons. Atribución-NoComercial-CompartirIgual (cc) EY-NC-sa $\underline{4.0 \text { Internacional }}$

Haller, Sofía Clara "Malvinas y el mundo: registros portuarios históricos de las islas (1826-1832 y 1842-1914)", Prohistoria, Año XXIII, núm. 34, dic. 2020, pp. 315-337.
} 
En este artículo ${ }^{1}$ se describen los registros portuarios históricos de las islas Malvinas y se analiza su importancia para estudiar las conexiones navieras del archipiélago. También se exploran sus múltiples posibilidades para ahondar en estudios específicos. En primer lugar, se considera el registro portuario realizado entre 1826 y 1832, bajo la administración rioplatense. Este documento se encuentra actualmente digitalizado en el Archivo General de la Nación (de aquí en adelante AGN), en el Fondo Documental Luis Vernet (Sala VII, FLV, Legajo 129, Carpeta 61). ${ }^{2}$ En segundo lugar, se considera el registro realizado bajo la administración británica, entre 1842 y 1914, que se encuentra transcripto por el Archivo Jane Cameron, ${ }^{3}$ domiciliado en Puerto Stanley, ${ }^{4}$ y que está disponible para la consulta en su sitio web. El archivo transcripto y publicado se extiende, en su totalidad, entre 1842 y 1947 y compone un total de 9 volúmenes. La información se ha analizado y descripto en el marco de la realización de una tesis doctoral, enfocada en considerar las conexiones de la región a nivel regional y global. La descripción de las fuentes ha sido considerada desde 1826, año en el que el registro comienza a tener lugar bajo el mandato rioplatense, hasta 1914, cuando la relación del mar austral con el resto del mundo terminó por cambiar cualitativamente, principalmente por la apertura del canal de Panamá que transformó por completo la navegación entre el Atlántico y el Pacífico. La documentación de los registros portuarios malvinenses contiene información valiosa en términos cuantitativos $\mathrm{y}$ cualitativos.

Las fuentes se abordan en línea con lo trabajado por Lorenz (2011, 2013), quien sostiene la necesidad de reconstruir el pasado malvinense conforme a una cronología que no se limite a los hitos de la ocupación británica de las islas por la fuerza en 1833, la denuncia del colonialismo, o el conflicto bélico de 1982 entre Argentina y Gran Bretaña. Lorenz ha enfatizado la importancia de integrar en la narrativa histórica a los distintos actores que formaron parte del

\footnotetext{
1 Un trabajo preliminar a este artículo se expuso en forma oral en el Primer Seminario Internacional de Historia Sudatlántica "Berma de Tormenta" que tuvo lugar en el Museo Malvinas e Islas del Atlántico Sur en septiembre del 2017.

2 Caviglia (2015) ha realizado una transcripción de este documento en su libro Malvinas: Soberanía, Memoria y Justicia.

3 http://www.nationalarchives.gov.fk

${ }^{4}$ En este artículo se utiliza "Puerto Stanley" para referise al poblado principal de las islas Malvinas. Puerto Stanley fue fundado con ese nombre en 1845, es decir con posterioridad a la ocupación británica de 1833. Esta denominación se mantuvo con excepción del período comprendido entre abril y junio de 1982, durante la guerra, cuando la Junta Militar en el poder en la Argentina bautizó la localidad como "Puerto Argentino". Con idéntico criterio se atiende a la toponimia que se utiliza en cada registro documental portuario, identificando como "Puerto Soledad", y no "Puerto Louis" al emplazamiento malvinense anterior a 1833, situado en otra bahía al noroeste de la de Stanley. Allí se había fundado la colonia encabezada por Luis Vernet, colonia a la cual el dominio británico le fue impuesto por la fuerza en 1833.
} 
pasado regional, ${ }^{5}$ cuya complejidad de relaciones no se alcanza a explicar solamente en el marco de cada historiografía, argentina o británica, ni con fuentes exclusivas de uno u otro archivo. En esta línea, los registros portuarios de las Islas Malvinas son fuentes que pueden contribuir, por ejemplo, al estudio de temas tan diversos como el desarrollo de la economía malvinense, la South American Mission Society en isla Keppel o la explotación de lobos marinos en la región por parte de tripulaciones y compañías provenientes de distintos lugares del globo. La descripción y el análisis de las fuentes $\mathrm{y}$, en definitiva, las relaciones marítimas históricas de Malvinas permiten comprender la importancia del archipiélago a nivel global y regional, descubrir qué navíos fondeaban en sus puertos y con qué necesidades, y qué conexiones tenían las islas y cómo fueron transformadas.

En términos regionales, las conexiones marítimas del mar austral presentan diferentes antecedentes y sobre todo un creciente y renovado interés en los últimos años. Como se ha considerado en un trabajo preliminar (Haller y Vezub, 2018), este interés está bien fundamentado: el territorio presentó entre 1800 y 1914 una importancia eminentemente marítima para distintas potencias del hemisferio norte. Desde fines del siglo XVIII el mar austral fue frecuentado por loberos y balleneros provenientes de Estados Unidos, Francia y Gran Bretaña. Los navíos cinegéticos que frecuentaron la costa continental de Patagonia y las islas antárticas utilizaron el archipiélago como lugar de explotación o bien para recalar y obtener provisiones, principalmente agua y carne, proveniente del ganado cimarrón suelto en las islas. Los registros portuarios permiten, entre otras cuestiones, vislumbrar el tráfico de los navíos dedicados a esta la explotación de mamíferos marinos. El mar austral también fue un lugar de circulación para aquellas naves que vinieron o se dirigieron hacia o desde el Pacífico y, que en su ruta, debieron rodear el Cabo de Hornos o atravesar el estrecho de Magallanes. La colonia británica de Malvinas se benefició económicamente del lugar estratégico de las islas, y brindó refugio, servicios de reparación y aprovisionamiento a los navíos que paraban allí. Fue de esta manera como cimentó, hasta 1870, su economía (Michinton, 1985; Royle, 1985). Los registros portuarios asentados bajo la administración británica muestran cómo Malvinas ocupó no solo un rol de puerto de escala en la navegación global sino también un lugar en la explotación de recursos naturales de las costas aledañas y en la economía regional. Las entradas y salidas de navíos declaradas permiten hilar las relaciones que la colonia británica tuvo con

\footnotetext{
${ }^{5}$ En los últimos años, distintos trabajos han tomado pasos en esta dirección, considerando la historia del archipiélago o del mar austral desde preguntas innovadoras, capaces de profundizar en las conexiones del territorio insular a partir de perspectivas globales y/o regionales (Pierini y Beecher, 2012; Mayorga, 2017; García y Podgorny; 2017; Jiménez et al., 2018; Haller y Vezub, 2018, entre otros).
} 
Montevideo en el Río de la Plata y con Punta Arenas en el estrecho de Magallanes, en materia de aprovisionamiento y de relaciones comerciales.

Entre otras cuestiones, la información extraída de los registros portuarios ha podido relacionarse con los viajes provistos por las bases de datos balleneras publicadas en el sitio web whalinghistory.org, que integran información de viajes balleneros y loberos provenientes de Estados Unidos, Gran Bretaña y Francia. También se han relacionado las entradas y salidas de navíos con documentación encontrada en el AGN en Buenos Aires, en el Jane Cameron National Archive de Malvinas o en repositorios digitales de sitios como la página de Royal Museums Greenwich. ${ }^{6}$ En este sentido, se considera que el abordaje de estas fuentes se enriquece de una metodología capaz de integrar información heterogénea proveniente de distintos repositorios documentales, así como bases de datos de viajes históricos que se han publicado con propósitos académicos. Esto hace posible conectar distintas regiones del mundo con el archipiélago malvinense, y permite, puntualmente, estudiar el pasado de la expansión capitalista en esta región periférica. Si bien la historia del mar patagónico y de las islas Malvinas no puede y no debe definirse únicamente por su rol periférico en la economía mundial, es necesario entender su funcionamiento económico y logístico en el sistema global, que constituye una parte fundamental de su historia.

El registro portuario que fue asentado bajo el mandato del Río de la Plata entre 1826 y 1832, está, salvo declaraciones excepcionales, escrito en inglés. Su título es el de "Arrivals and Sailings of vessels touching at the East Falklands". Es posible que fuera realizado y completado por Matthew Brisbane, un lobero británico que se radicó en las islas Malvinas bajo la autoridad de Luis Vernet. Vernet fue el impulsor de la colonia de Puerto Soledad en Malvinas y el comandante político militar de las misma, autoridad que le confirió el gobierno rioplatense. Una lectura anacrónica de este documento puede dar lugar al debate, en términos soberanos, sobre la formulación de Falklands en vez de Malvinas o sobre el idioma inglés en el cual se inscribe el documento. Sin embargo, hay indicios que en la época las denominaciones "Malvinas" y "Falklands" operaron como una traducción del español al inglés. ${ }^{7} \mathrm{Al}$ menos en la primera mitad siglo XIX, en la Patagonia y en Malvinas, la soberanía del territorio no parece haberse tejido ni disputado por la trama del idioma, ni por la nacionalidad de quienes la habitaban. La población de la colonia era de origen diverso habiendo entre ellos rioplatenses, ingleses, alemanes, franceses, estadounidenses, aborígenes y afroamericanos esclavizados, a condición de ser liberados luego de cierta cantidad de años de trabajo (Lorenz 2014). Vernet

\footnotetext{
${ }^{6}$ https://www.rmg.co.uk/

${ }^{7}$ Entre otra bibliografía de la época, un artículo de un diccionario de geografía de 1853, editado en Londres, se explaya sobre las islas Malvinas y establece, a manera de traducción "French Malouines, Spanish Malvinas"(Johnston, 1853).
} 
mismo era hamburgués y fue nombrado comandante político militar de las islas Malvinas y hablaba en términos soberanos en nombre del gobierno del Río de la Plata. El lobero británico Brisbane fue el que arrestó en el nombre de este gobierno a las naves loberas estadounidenses Harriet, Breakwater y Superior, lo que meses después derivó en el ataque de la colonia de Puerto Soledad por parte del navío USS Lexington y sus tripulantes. ${ }^{8}$ Los actores que frecuentaban las islas Malvinas o que estaban asentados allí provenían de múltiples lugares y el contexto histórico global y regional hacía que abundara, en el mar austral en general, un ambiente cosmopolita y multilingüe que coexistía con las disputas gubernamentales por el territorio. La comprensión de la dinámica naviera y de la explotación de recursos permite este tipo de observaciones, que se acercan desde otro lado a la discusión histórica de la soberanía, las denominaciones o el tipo de relaciones transnacionales que se dieron y que se dan en las islas.

El documento producido bajo la administración rioplatense reúne un total de 109 declaraciones de anclajes. La documentación original tiene el formato de una planilla con varias columnas donde se completan los datos de cada anclaje, tituladas Arrival, Vessel's Name, Masters, Where From, Remarks, Where Bound, Date of Sailing. Este registro presenta detalles sucintos y permite caracterizar a la mayoría de los viajes según su propósito (en la columna de Remarks, se inscriben notas como Whaling, Sealing, Merchantmen, Trading Vessel, etc.). En términos generales, no se brindan observaciones sobre los motivos de entrada al puerto.

En cuanto a la documentación realizada por la administración británica, esta está organizada de manera similar a la producida por las autoridades rioplatenses. Entre 1842 y 1914 se encuentran un total de 4.644 registros a lo largo de un número de columnas repiten la misma información, algunas veces bajo un rótulo diferente: Date of Entry, Vessel's Name, Name of Master, Where Bound, Where From, Date Cleared. El archivo también detalla otras columnas de inscripción como Country, By Whom Entered (Notes), Tonnage, y Cargo or Ballast entre otros. La información completada y el número de columnas varían durante el período, ya que los criterios de registro tuvieron modificaciones, y las autoridades navales también cambiaron con el tiempo. En muchos casos hay campos que permanecen sin completar. El registro bajo la administración británica no dedica tanta atención a categorizar los viajes según su actividad, salvo en los casos de los viajes específicos como los de cacería, los postales y los científicos, lo que conlleva una complejidad adicional a la hora de sistematizar la información. Por otro lado, este segundo registro tiene una columna dedicada al motivo que acercó a los navíos a los puertos malvinenses, información significativa para entender los usos de los puertos. La información integra

\footnotetext{
${ }^{8}$ Fue un año después del ataque de la USS Lexington, en enero de 1833 que la nave HMS Clio llegó a Malvinas y los británicos expulsaron a las autoridades rioplatenses de las islas, imponiéndose en el territorio insular.
} 
anclajes producidos en puntos antárticos como como Georgias del Sur [Where Entered: South Georgia] o las Shetland del Sur [Where Entered: Deception / Deception Harbour Port Foster]. Estos puntos antárticos están incluidos en la transcripción del registro malvinense, y eran islas hacia y desde donde iban y provenían embarcaciones balleneras y loberas.

Para estudiar esta información de gran volumen se han volcado los datos a una planilla de cálculo y se ha hecho uso de palabras claves con el propósito de analizarlos. Estas herramientas han permitido clasificar en la documentación las banderas que enarbolaban los navíos que se acercaban, los motivos que los hacían ingresar en la costa malvinense, y el propósito de sus viajes (caza de mamíferos marinos, transporte de commodities, animales, distribución de correo, fines militares, etc.). Factores como el año del anclaje, el cargo, el destino o la proveniencia, han permitido considerar que ciertos viajes transitaron por las Malvinas bajo el impulso de la fiebre del oro en California y Australia, el auge del guano en el Pacífico, así como otras rutas específicas en las que se utilizaba el archipiélago como escala.

\section{Puerto Soledad y la administración rioplatense (1826-1832)}

Entre 1826 y 1832 se declararon 31 anclajes por parte de navíos que se dirigían al Pacífico, y otros 19 que seguían la ruta inversa. El movimiento portuario fue mayormente producido por los navíos que se dedicaban a actividades de cacería de mamíferos marinos (las observaciones en estos anclajes declaran Sealing y Whaling) y en segundo lugar por navíos mercantes. Las embarcaciones navegaban en su mayor parte bajo la bandera estadounidense y la británica, y en mucho menor medida bajo la de Francia y de Buenos Aires. Las Malvinas constituyeron en este período un lugar de recalada para balleneros y loberos estadounidenses y británicos más que para otro tipo de tripulaciones. Los navíos declararon provenir sobre todo de Londres, Cabo de Hornos y el Pacífico, Buenos Aires, Nueva York, Stonington y Boston. Sus destinos fueron mayormente el Pacífico o el pasaje de Cabo de Hornos, Londres, Statenland (que hace referencia la Isla de los Estados) y Buenos Aires.

El acceso a las diferentes bases de datos balleneras provenientes de Estados Unidos, Gran Bretaña y Francia, publicadas en el sitio whalinghistory.org ha permitido entretejer los datos allí recabados con los anclajes declarados en los registros portuarios. Con respecto a las fuentes de las bases de datos, mucha información se ha extraído, aunque no de manera excluyente, en registros oficiales de puertos, reportes de pesca, prensa de distinto origen y en algunos casos específicos, la Whaling Shipping Lists estadounidense o la Lloyd's List británica. Aunque los viajes fueron registrados como vinculados a la industria ballenera, las fuentes documentales regionales indican que muchos de estos se 
dedicaban a la caza de lobos. El cotejamiento entre bases de datos y fuentes documentales permitió tantear las posibilidades y los límites de ambas, llamando la atención sobre las contradicciones de los documentos y las dificultades para rastrear actores que por definición eran itinerantes. Un número de viajes que se encuentran en el registro, por ejemplo, no aparecen en las bases de datos, o aparecen con destino hacia lugares diferentes a los de Malvinas o Patagonia (se lee, por ejemplo, Banks of Brazil o South Atlantic en destinos de navíos que luego se encuentran en Malvinas). Ello permite inferir que hay más viajes que se dirigieron a la región que los presentados en los datos oficiales. En otros casos la información brindada por las bases de datos se complementa con la del registro naviero.

Por ejemplo, el Sprigthly (capitán Norris) zarpó, según la base de datos británica, de Londres en 1825. En octubre de 1825, se encontraba en Río de Janeiro y en febrero de 1826 en las afueras de la Isla de Gough (o isla de Diego Alvarez, coordenadas 40 $19^{\prime}$ S, 9o $55^{\prime}$ O), luego de lo cual los registros malvinenses lo reportan en Malvinas. Es una de las primeras entradas declaradas en el registro rioplatense en junio de 1826, con la leyenda en las observaciones: Sealing, lo que indica que se dedicaban a la caza de lobos o elefantes marinos. En septiembre, el navío continuó su camino hacia Cabo de Hornos. El Sprigthly volvió a Malvinas en enero y luego en abril de 1827, declarando que provenía, en ambas oportunidades, de las mismas islas. Es probable que la tripulación del Sprightly se dedicara durante esos diez meses a lobear entre el estrecho de Magallanes, las islas aledañas y el archipiélago. El registro de Malvinas indica que luego de su último anclaje el navío se dirigió a Londres. Según los datos oficiales provistos por el sitio Whalinghistory.org, llegó a casa en julio de 1827, 698 días después de haber partido. Las notas en la base de datos sugieren que quizás se tratara de un trading voyage, sin embargo, las idas y venidas de Malvinas y las declaraciones en el registro indican que se trataba de un viaje lobero. Este tipo de triangulaciones con información proveniente de las bases de datos balleneras británica, estadounidense y francesa, son posibles de trazar en un gran número de viajes, lo que aporta información en materia de los derroteros de los mismos.

En relación a los navíos mercantes que entraron a Malvinas entre 1826 y 1832, estos declaran principalmente su origen en Hamburgo, la Isla de los Estados, Buenos Aires y Tasmania. Sus destinos fueron sobre todo Londres, Valparaíso y Buenos Aires. Nueve de los navíos mercantes se quedaron una semana o menos y doce tuvieron estadías más prolongadas, que variaron entre los 11 y 47 días. Es probable que la mayor extensión de las estadías se debiera a la necesidad de realizar reacondicionamientos o reparaciones. Los diversos destinos y proveniencias no indican patrones precisos de este tipo de viajes: las rutas mercantes son dispersas y sugieren que la recalada en las Malvinas era generalmente incidental, aunque no se descarta que circulara para entonces 
cierto conocimiento de la existencia de Puerto Soledad como enclave naviero. Parte del problema que se desprende del análisis es que en la documentación que componen los registros navieros conviven dos tipos de declaraciones: aquellas que asientan el puerto inicial o final de origen o de destino (como Londres o Boston) y aquellos que mencionan un anclaje inmediato o intermedio (como Cabo de Hornos o la isla de los Estados). En este sentido, no es posible precisar cuáles de estos movimientos indicados fueron de cabotaje, de media distancia o de escala en una ruta más larga.

En términos generales ( $\mathrm{y}$ en relación a la posterior administración británica de las islas), las perspectivas de Puerto Soledad como puerto de escala para los viajes comerciales que seguían la ruta hacia o desde el Pacífico fueron acotadas, lo que obedece a un número de razones. Entre ellas, que la colonia se sostuvo durante un período muy breve, y que el puerto donde estaba ubicada, en bahía de la Anunciación / bahía Berkeley, es poco profundo y de difícil acceso. Es posible que también hubiese una estrategia limitada por parte de la autoridad isleña y del gobierno rioplatense, en vistas al potencial marítimo de las islas. Si se observa el modo en que están organizadas las planillas de los registros navales durante la administración de Vernet, estos documentos no incluyen el asiento de la declaración de las razones de la entrada al puerto de cada embarcación, a diferencia de la documentación inglesa. El gobierno británico, que por oposición contaba con amplia experiencia en asuntos marítimos, así como una fuerza naval y marina mercante de importancia, no solo se dedicó a documentar los motivos de ingreso al puerto, sino que durante su administración realizó una serie de operaciones estratégicas de infraestructura y divulgación dedicadas a explotar el potencial marítimo del archipiélago. Pero además de ello, y esto fue fundamental, las islas contaron con un flujo de navíos importante que estuvo motivado por distintas dinámicas extractivas que tuvieron su auge en la segunda mitad del siglo XIX.

\section{Puerto Stanley y la administración británica (1842-1914)}

Algunos antecedentes que abordan las actividades económicas luego de la ocupación británica establecen un lineamiento de cómo sucedieron los acontecimientos y procesos de la economía malvinense, primero dependiendo de sus actividades como puerto de escala entre 1850 y 1870, y luego de sus actividades pecuarias a partir de la década de 1870 (Royle, 1985; Minchinton, 1985). Estos autores plantean que, luego de la ocupación de las islas Malvinas, el gobierno británico pidió a la "Colonial Land and Emigration Commissioners" evaluar las perspectivas de su rentabilidad económica. Entre las diversas posibilidades que se consideraron, tuvieron prioridad el establecer una estación de reacondicionamiento para los barcos mercantes $\mathrm{y}$, asimismo, que las islas se 
convirtieran en una estación y depósito para las fuerzas navales (Royle, 1985; Minchinton, 1985). Luego de diversos relevamientos, en 1845 se efectuó la mudanza de la administración de Puerto Soledad a Puerto Stanley, cuyo fondeadero, a donde se ingresa desde la entrada de puerto William, es más profundo, amplio, de más fácil acceso y cuenta con mejor visibilidad. James Clark Ross, un oficial británico que terminó por determinar este cambio en 1842, estableció que la principal objeción del traslado era la poca cantidad de tierra que rodeaba a puerto William que podía usarse con propósitos agriculturales. Según Ross, esto carecía de importancia en tanto las ventajas de conservar las islas estaban conectadas con asuntos marítimos, y puerto William era ampliamente superior a bahía de la Anunciación/Berkeley en términos navales (Ross, 1847: 260). A pesar de eso, en 1847 el gobernador isleño Richard Clement Moody, nombrado por las autoridades de Gran Bretaña, manifestó que eran pocos los navíos que entraban al puerto. Unos años más tarde el tráfico se intensificó por la ruta de cabo de Hornos, lo que ha sido atribuido a la explotación del guano peruano y a las fiebres de oro australianas y californianas (Royle, 1985). Para fines de 1850 las islas Malvinas comenzaron a reportar los éxitos de la colonia como un lugar para la provisión de recursos para los navíos, cumpliendo incluso el rol de salvataje en los casos de naufragios. La industria y el comercio marítimo proveyeron a la población de la isla que crecía durante aquellos años (Royle, 1985).

En la década de 1870 las reparaciones de barcos llegaron a su pico máximo y comenzaron a decaer, lo que ha sido atribuido a diferentes razones (Michinton, 1985; Royle, 1985): 1) el British Board of Trade no permitió que los barcos viejos rodearan el Cabo de Hornos, 2) la construcción del ferrocarril transcontinental en Estados Unidos permitió el transporte de trigo de San Francisco a Europa sin circunnavegar el continente, 3) la apertura del canal de Suez en 1869 modificó la cantidad de navíos que tomaban la ruta por el Cabo de Hornos, 4) la declinación de los barcos a vela ante los barcos a vapor hizo que la navegación por el Estrecho de Magallanes fuera más segura, posibilitando también que los viajes de los navíos de mayor calado fueran más rápidos, lo que permitió un almacenamiento mayor de agua y alimentos. Todas estas razones llevaron a la recesión de las reparaciones navales como industria de cabecera en las Malvinas. Para entonces, la ganadería se había expandido y tuvo su turno en la sustentabilidad del archipiélago. Se ha señalado que para 1876 las islas eran autosuficientes y que su prosperidad dependía de los productos derivados del ganado ovino. 


\section{Figura 1}

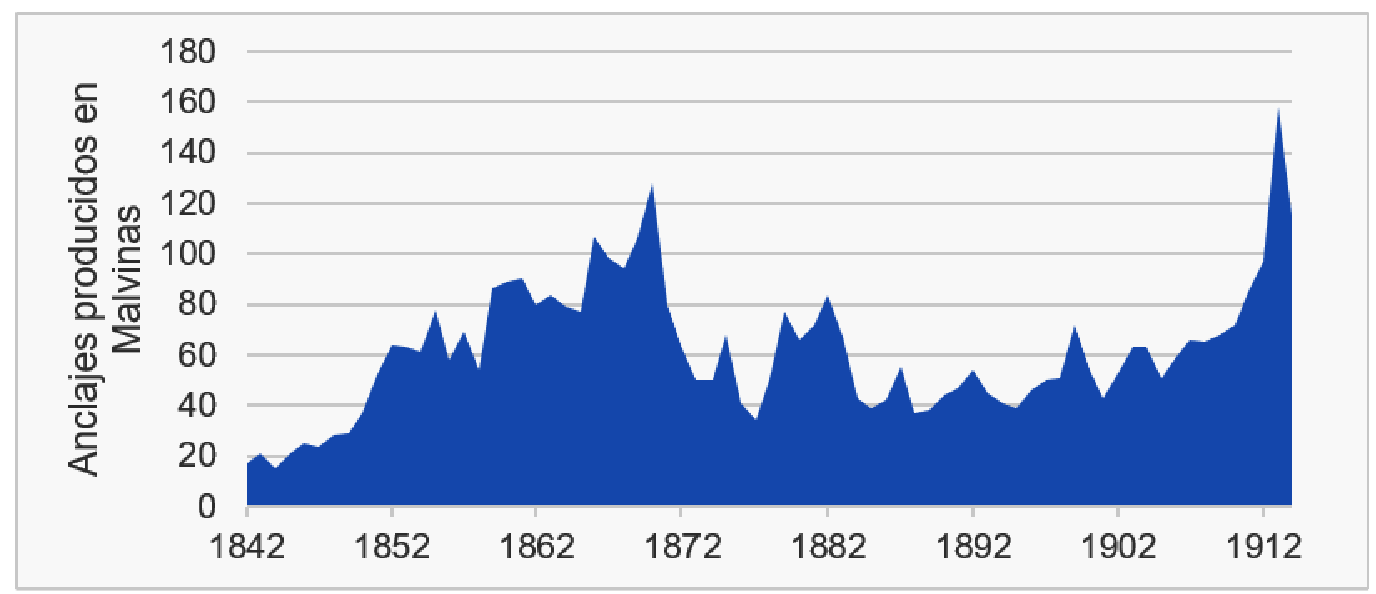

Anclajes en Malvinas (1842-1914). Elaboración propia a partir de los registros de entradas y salidas de Malvinas.

En la figura 1 se puede ver la actividad portuaria declarada en el archipiélago malvinense durante setenta y dos años. El gráfico respalda a los antecedentes respecto del incremento naviero entre 1850 y 1860, en contraposición a la década de 1840. También se observa la declinación de anclajes para 1870, y algunos vaivenes en las décadas que siguieron, que culminaron con nuevo crecimiento en la actividad portuaria entre 1910 y 1914. Este último pico se explica por un número elevado de anclajes provenientes y con destino a Sandjeford, Noruega, provenientes de South Georgia y New Island. Estos navíos estaban dedicados a la cacería de lobos y ballenas en el mar austral, o que se encontraban realizando viajes colaterales a esta actividad (en materia de provisiones y maquinaria necesaria). Durante esos años también se observa un número creciente de anclajes por parte de navíos británicos dedicados a distribuir correo. Hacia fines de 1914 también ocurrió la Batalla de Falklands entre las armadas británica y alemana, lo que ocasionó que varios barcos de guerra ingresaran al puerto.

Una vez producida la mudanza de la administración a Puerto Stanley, el Almirantazgo británico y la Falkland Islands Company (FIC) se dedicaron a difundir el nuevo "puerto libre": de manera estratégica y en esa dirección, Puerto Stanley no cobró gravámenes a los navíos extranjeros que lo visitaban hasta 1870. Las cercanías del puerto fueron balizadas, se instaló un mástil pintado de rojo y blanco en el cabo Pembroke para señalizar la entrada al puerto en 1840, que quince años después fue reemplazado por un faro prefabricado en Gran Bretaña. Estas modificaciones fueron simultáneas con publicidad y difusión en distintos idiomas, dedicadas a divulgar la mudanza y 
sus múltiples ventajas, ${ }^{9}$ y dirigidas a los capitanes de barco, tripulaciones y compañías que frecuentaban la ruta por Cabo de Hornos. Se señalaron las ventajas marítimas de la nueva ubicación: fácil acceso, balizas, refugio, protección, servicio de pilotaje y precios adecuados. Los precios se comparaban con las tasas altas que se cobraban en los puertos sudamericanos, particularmente los brasileros. La FIC se publicitó como una entidad proveedora de provisiones, carbón y reparaciones de toda clase, provista de equipamiento de buceo para efectuar reparaciones en los cascos de los navíos. Esta información también fue difundida en diferentes guías de navegación de la región que ofrecían instrucciones específicas relativas a la hidrografía, los vientos y el clima (Parker King y Fitz Roy, 1860; Findlay, 1867; Dupont, 1849).

La publicidad y la circulación de información tuvieron sus frutos. Un número importante de los navíos que ingresaron a Stanley entre 1842 y 1914 registró haberlo hecho con necesidad de reparaciones $(n=295)$, agua $(n=294)$ y provisiones $(\mathrm{n}=280)$. En muchos casos estas necesidades eran mixtas. En menor medida, los barcos se dirigieron al puerto en busca de asistencia médica o de carbón. Algunos viajes aislados también interrumpieron su curso para reclutar tripulación, por causa de incendio o "carbón caliente" [Coal heated], una reacción que hacía peligroso el transporte de este combustible. Estos anclajes incluían en ocasiones la leyenda "In distress", dando idea del peligro de estas diferentes causas de ingreso. Los registros permiten ver cómo, cronológicamente, las necesidades de agua y provisiones llevaron a un pico de actividad portuaria en 1850 y comenzaron a declinar durante la década de 1870, tal como sostienen los antecedentes sobre la historia económica de las islas (Royle, 1985; Minchinton, 1985). En cuanto a las necesidades de reparaciones, estas continuaron en menor medida hasta 1900. Para 1880, la búsqueda de agua prácticamente dejó de figurar como motivo de ingreso al puerto, y la necesidad de provisiones también declinó, lo que da cuenta del impacto que la rapidez de la tecnología del vapor aplicada a los barcos, así como la mayor capacidad de almacenaje de los navíos, causaron en la actividad portuaria malvinense.

Respecto a la bandera bajo la cual ingresaron los navíos a Malvinas entre 1842 y 1914, esta fue mayormente británica. Es de destacar que los anclajes por parte de navíos locales se declaraban como británicos. En menor medida los navíos navegaban bajo la bandera de Alemania, Estados Unidos y Noruega. Una gran mayoría de viajes británicos que pasaron por las Malvinas asentaron que transportaban mercancías (principalmente carbón, guano y lana, pero también minerales, animales, trigo y maquinaria), y en segundo lugar que tenían por misión distribuir correo. Los navíos norteamericanos tuvieron

\footnotetext{
9 Ejemplos de estas publicidades, relativas a las ventajas Marítimas de Puerto Stanley pueden encontrarse en el AGN (FLV, Sala VII, Leg. 134, C. 55.) y en el "Printed chart of part of East Falkland island, Stanley Harbour" disponible en la colección digital de la página de Royal Museums Greenwich, Ub. G214:13/10.
} 
presencia sobre todo en el primer período de la colonia británica con propósitos cinegéticos, aunque también estaban involucrados en el transporte de mercancías. Hacia fines del siglo XIX comenzó la actividad ballenera por parte de embarcaciones noruegas en el archipiélago y en las islas antárticas, y sus anclajes incrementaron hacia 1914. Los viajes por parte de navíos alemanes aparecieron de manera sostenida entre 1880 y 1900, período en el cual la corona inglesa contrató a la compañía alemana Deutsche Dampfschiffahrtsgesellschaft Kosmos (DDG Kosmos), para distribuir el correo en Malvinas (Howat 1989). El archipiélago pasó a integrar un servicio regular dentro de una red más amplia con Europa y Sudamérica y una comunicación intensa con Hamburgo y la costa oeste sudamericana. Luego, la Pacific Steam Navigation Company (PSNC) fue contratada para distribuir el correo de Malvinas, y mantuvo una ruta entre Liverpool y Valparaíso con escalas en, entre distintas ubicaciones, Punta Arenas. Esta ciudad magallánica se volvió para 1870 una importante conexión de las islas en materia de rutas postales y comercio regional, y un punto de circulación frecuente de pasajeros con las Malvinas (lo que ha sido trabajado por Martinic, 1996, 2009).

\section{Figura 2}

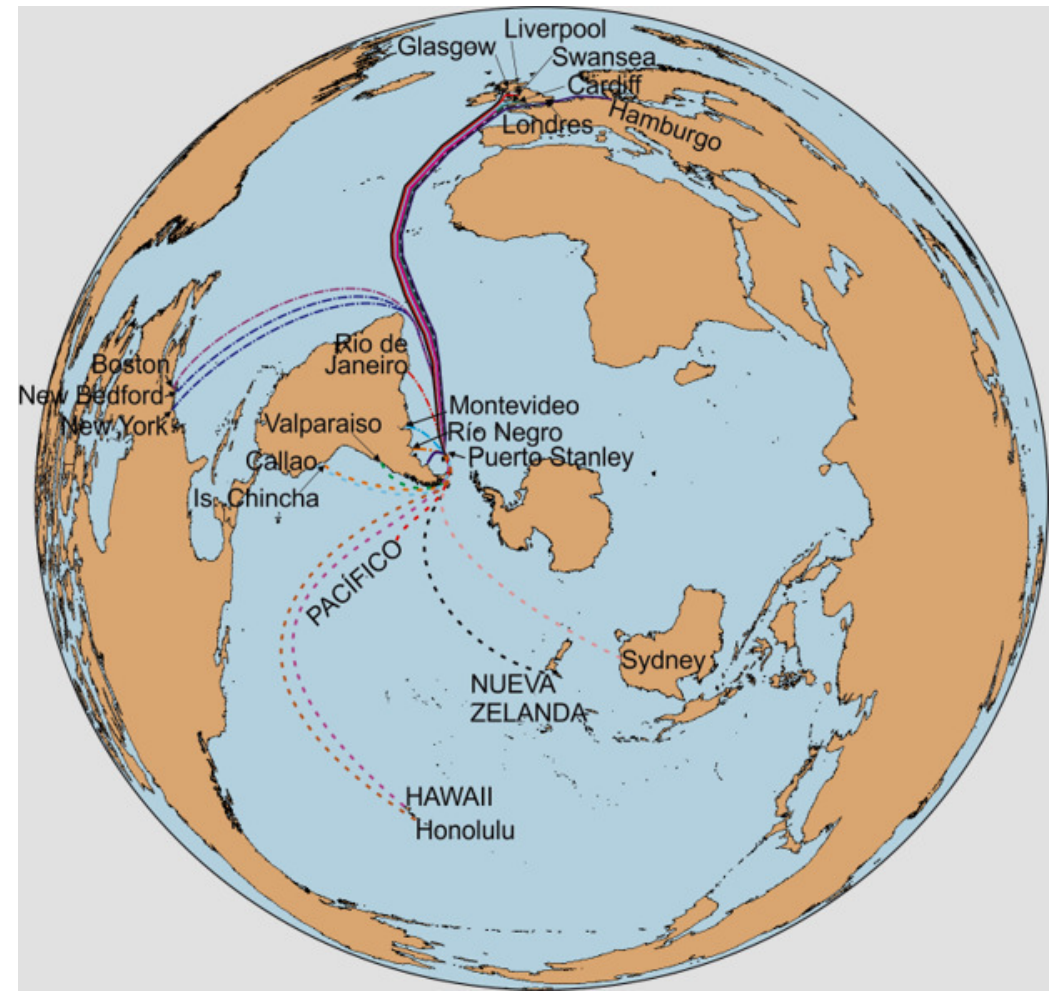

Rutas hacia Malvinas (1842-1869). Proyección Azimutal Equidistante. Elaboración propia a partir de los registros portuarios. Incluye rutas provenientes de orígenes repetidos en 10 o más oportunidades. 


\section{Figura 3}

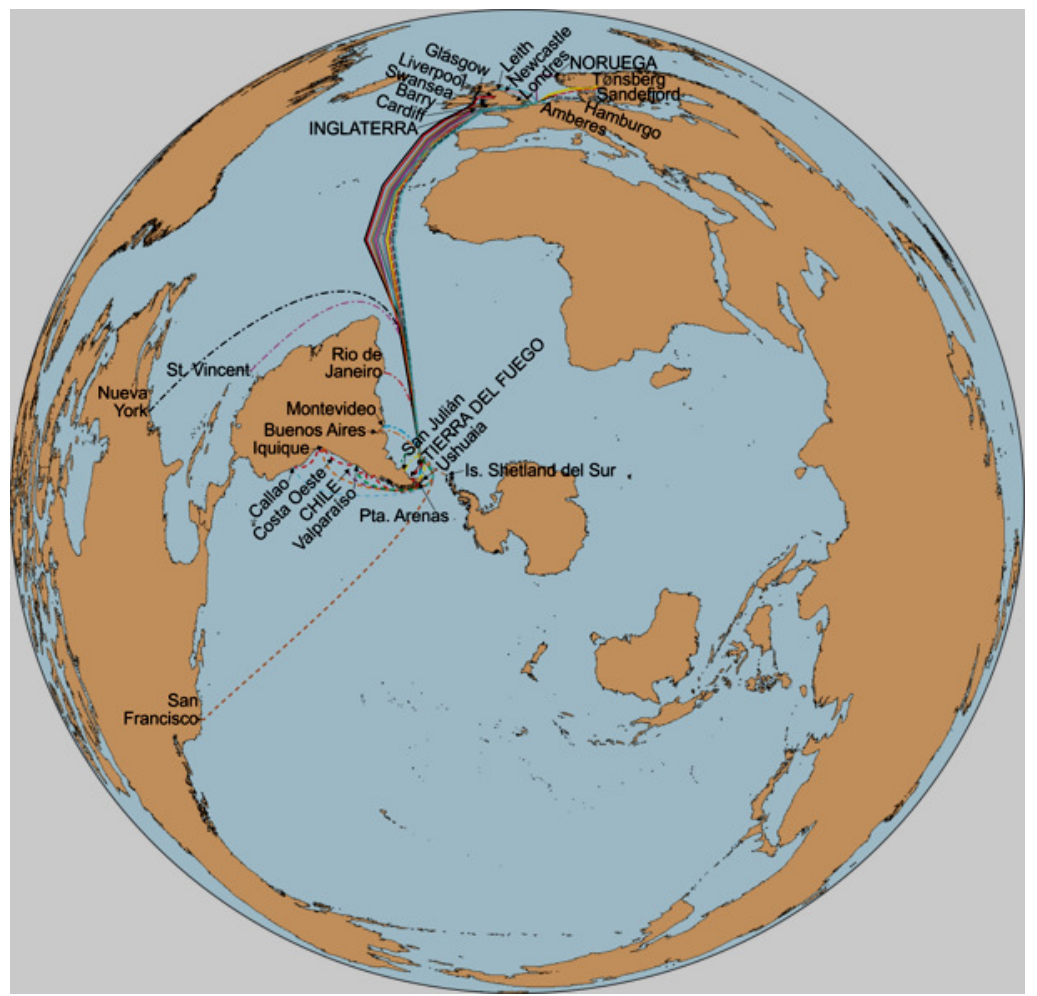

Rutas hacia Malvinas (1870-1914). Proyección Azimutal Equidistante. Elaboración propia a partir de los registros portuarios. Incluye rutas provenientes de orígenes repetidos en 10 o más oportunidades.

Los mapas de las figuras 2 y 3 permiten visualizar las diferentes proveniencias de los navíos que llegaron a Malvinas entre 1842 y 1869, y 1870 y 1914. Se han tomado decisiones con el fin de evitar los mapas "planos" de proyección tradicional, en línea con lo trabajado por Bascopé (2018). Este autor retoma a Dodds cuando sostiene que la perspectiva "norte-sur", o de "fin del mundo", corresponde a la época de los "geógrafos militantes", agentes metropolitanos que luego de explorar la región diseñaron imágenes australes y extremas al servicio de la administración imperial o del Estado nacional para el que trabajaban. Esta perspectiva fue transmitida del período colonial al período nacional de administración política, a través de diferentes textos jurídicos y acumulaciones de imágenes geográficas. Los mapas actuales, con sus proyecciones planas y disecciones geográficas, trastocan las dimensiones y fronteras del territorio austral, y las distancias que sugieren son engañosas. Es por esto por lo que la cartografía desplegada ha incorporado la proyección sobre la Antártida, que permite relativizar las distancias geográficas de las rutas históricas, y representar el eje en la "periferia" patagónica. La proyección elegida, Azimutal Equidistante, ayuda a visualizar las Malvinas como centro de las redes globales y regionales que se tejían a su alrededor. Aun cuando muchas de las rutas que implican estos viajes se generaban desde una lógica centro- 
periferia, ubicar a las islas Malvinas en el centro del mapa facilita entender su posición estratégica en las conexiones navieras subpolares.

Los registros portuarios muestran una relación importante con Gran Bretaña y otras potencias europeas, pero también con Estados Unidos, el Río de la Plata y algunos puntos del Pacífico y Oceanía. También revelan una intensa relación con Montevideo entre 1842 y 1914. El puerto oriental fue una escala fundamental en las rutas que involucraban al archipiélago, en particular para aquellos viajes destinados a distribuir correo, y en menor medida para aquellos dedicados al transporte de mercancías o con propósitos cinegéticos que provenían de Noruega durante el último tercio del siglo XIX. Montevideo fue un gran proveedor de la colonia: los navíos postales y comerciales que zarpaban de aquel puerto declararon cargamentos generales, y en algunos casos el transporte de productos específicos como harina, fruta, papas y especias, o animales como caballos y ovejas. En varios casos los cargamentos eran consignados a un residente malvinense, a la FIC o "al gobierno". Entre 1870 y 1914 se intensificó esta comunicación a causa de las rutas postales desplegadas por la DDG Kosmos y la PSNC. Montevideo también era un puerto de escala para los navíos noruegos loberos y balleneros. Por último, desde este puerto figuran muchos viajes con pasajeros que eran tipificados como gauchos, peones, colonos o autoridades. Algunos archivos presentes en el Jane Cameron National Archive $^{10}$ dan cuenta que, en su primera etapa, la colonia británica de Malvinas se benefició transportando a Malvinas mano de obra rural y caballos provenientes del Río de la Plata para obtener el ganado suelto en las islas y proveer con él a los colonos y a los navíos que llegaban. En el libro "Malvinas: hombres, ganados y tecnología rural criolla (siglo XVIII y XIX)" (Jiménez et al. 2018) se ilustra minuciosamente la necesidad de contar con personas en buenas condiciones de asegurar la captura y el tratamiento posterior a los animales en el archipiélago. Los gauchos llevados a Malvinas construyeron los "hunting corrals" en las islas, grandes cercos circulares de piedra para encerrar el ganado, que aún se mantienen en pie (lo relativo a estos corrales ha sido trabajado por Spruce, 1992). Estas operaciones por parte de las autoridades británicas fueron estratégicas para establecer los cimientos de la industria pecuaria malvinense.

En cuanto a las conexiones con Gran Bretaña, desde Londres y Liverpool solían enviarse productos específicos y transportar pasajeros a la colonia, pero el tránsito de los navíos británicos involucraba en muchos casos el cargamento de bienes hacia otras regiones del mundo. La conexión con Gran Bretaña se intensificó después 1870, y otros puertos europeos también tuvieron conexiones con las islas. Muchas rutas se originaban en diferentes ubicaciones del océano Pacífico. Los navíos que partían desde San Francisco con escala en las Malvinas solían tener cargamentos de cereales como el trigo, mientras que los

${ }^{10}$ Jane Cameron National Archive. Miscellaneous Letters - Outward - B1. Carta del Gobernador Moody al Government House, 27 de mayo de 1842. 
provenientes de las islas Chincha y Callao en Perú transportaban guano. En menor medida, los flujos navieros provenían de Valparaíso o puertos como Sidney y Nueva Zelanda. La relación entre Oceanía y las Malvinas se estableció entre 1842 y 1869 (Fig. 2), y perdió importancia entre 1870 y 1914. Las conexiones producidas por la actividad lobera o ballenera fueron entre 1842 y 1869, con Honolulu en Hawaii, South Shetlands en la Antártida y New Bedford en Connecticut y, después de 1870, con Noruega, las islas antárticas y San Vicente.

Los registros entre 1842 y 1914 permiten considerar rutas recurrentes que utilizaron los puertos de las islas Malvinas, mediante el establecimiento de patrones con las mismas proveniencias y destinos, que mantenían una escala relativamente estable en el archipiélago. Un número importante de navíos que visitaban las Malvinas conectaban distintos puertos británicos con puertos chilenos, posiblemente con motivo de la explotación minera efectuada en el país sudamericano. Entre 1840 y 1870 la conexión de Gales con la industria chilena de cobre era importante (Llorca-Jaña, 2016), y se daba en términos de traspaso de tecnología de fundición y exportaciones: en las minas de cobre de Caldera, se utilizaba carbón proveniente tanto de Chile como del puerto galés de Swansea, en tanto se consideraba que esta mezcla daba mejores resultados que cuando se quemaban por separado (Centner, 1942). Los barcos de Swansea y Cardiff que se dirigían hacia puertos chilenos como Valparaíso, Coquimbo, Iquique y Antofagasta con cargamentos de carbón, posiblemente lo hayan hecho por este motivo.

Entre 1842 y 1869, la ruta hacia California o San Francisco se volvió un motivo de paso por las Malvinas (como mencionan Royle, 1985 y Minchinton, 1985). En este período la costa oeste de Norteamérica fue el destino más frecuente para los navíos que anclaban en Malvinas, principalmente por aquellos provenientes de Liverpool, Londres y Nueva York. En segundo lugar, le siguieron destinos británicos como Londres, Cork (un puerto frecuentado por los navíos con cargamento de guano) y Liverpool. Entre 1870 y 1914 Montevideo, Liverpool, Punta Arenas y Callao se volvieron los destinos de mayor importancia, ya que conformaban la ruta postal que integraba el archipiélago.

Las Malvinas formaron parte de un entramado portuario que cumplía un papel de escala en diferentes rutas interoceánicas. Las rutas que implicaban mayor actividad portuaria eran las postales (categoría en que se registran la mayoría de los anclajes pertenecientes a los navíos de la DDG Kosmos y la PSNC Company). También era importante el rol de Puerto Stanley como escala hacia los territorios de caza de lobos y ballenas, los viajes relativos a la actividad minera y guanera en el Pacífico sudamericano, así como la conexión que implicaba con California, no solo durante el auge de la fiebre de oro que se dio 
entre 1848 y 1855, sino incluso posteriormente con un promedio de dos viajes por año entre 1856 y 1899.

\section{Las Malvinas como epicentro de la red marítima patagónica}

Si bien la lógica de la economía centro-periferia fue un aspecto importante en la consolidación de la colonia británica de Malvinas, también existían dinámicas regionales de navegación. En el registro Entradas y Salidas de Puerto Soledad entre 1826 y 1831, unos doce anclajes por parte de navíos registraron provenir de puntos de la región como Patagonia, Río Negro, Coast of Patagonia, la Isla de los Estados o el Estrecho de Magallanes. Esta circulación la realizaban barcos que recorrían las costas cazando mamíferos marinos, y otros que llevaban cargamentos para Puerto Soledad desde Río Negro o "Patagonia". También hubo navíos que provenían de la Isla de los Estados y el Estrecho de Magallanes. Los tripulantes de estos últimos viajes actuaban como consignatarios de Vernet, y se dedicaron a explorar la región y a traer madera, ${ }^{11}$ de la que el archipiélago malvinense carecía.

A partir de 1842 el flujo interregional continuó con mayor intensidad y hacia diferentes ubicaciones. Existía una fluidez con diferentes puntos de la costa continental y la isla de Tierra del Fuego. Asimismo, se destacan las relaciones con las islas antárticas. La figura 4 representa estas conexiones con proyección del mapa regional sobre el Polo Sur. Nuevamente, esta proyección es útil porque permite entender la cercanía y la dinámica de las conexiones regionales con el archipiélago en el centro del mar austral: el lugar de Malvinas en este centro es completamente estratégico desde el punto de vista regional.

${ }^{11}$ AGN, FLV, Sala VII. Legajo 129, Carpeta 74. Apuntes sobre la Isla de los Estados. 


\section{Figura 4}

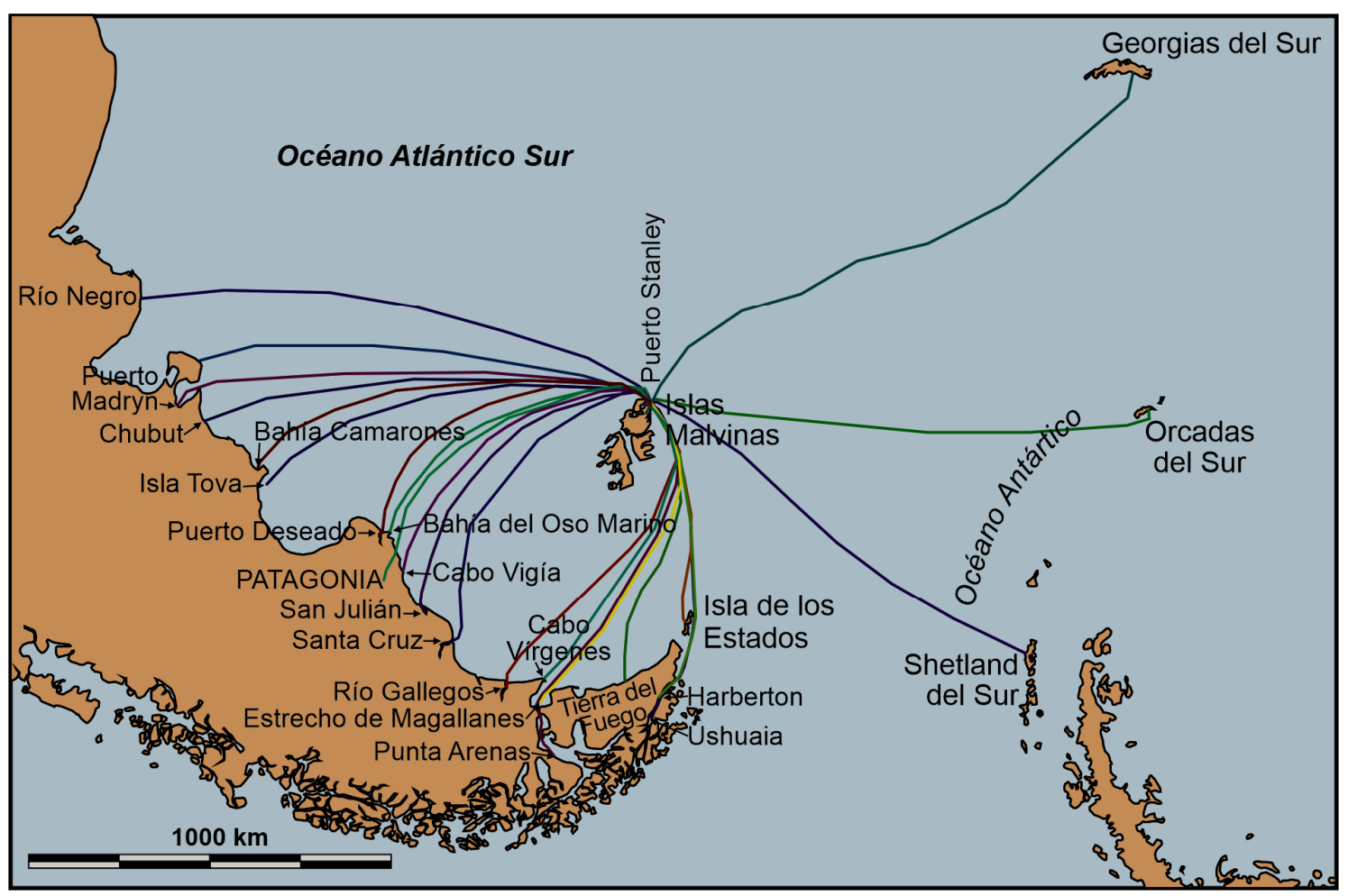

Las conexiones regionales del archipiélago Malvinense (1842-1914). Elaboración propia a partir de los registros navieros.

Entre 1842 y 1869 "Patagonia”, Río Negro y Tierra del Fuego aparecieron en gran parte de los registros dando cuenta de una interconexión importante para el tráfico isleño, aunque menor al caudal que se recibía desde Montevideo o Londres. Después de 1870, Punta Arenas se reveló como un nodo portuario fundamental en la economía regional (los registros muestran 330 anclajes provenientes de esta localidad entre 1842 y 1914). Las categorías imprecisas como Coast (término que se utilizaba para hacer referencia a la Patagonia continental) o Patagonia se repitieron, lo que impide conocer con exactitud la procedencia de muchos viajes. Aunque, como indica diferente documentación de la época, es probable que "Patagonia" hiciera referencia a la localidad de Carmen de Patagones en muchos casos.

La dinámica regional muestra que, pese a los conflictos internacionales, la colonia británica en el archipiélago malvinense constituía un importante interlocutor de la economía patagónica y magallánica. La colonia malvinense estaba involucrada en los intercambios comerciales y de distintos sectores industriales como la ganadería, la caza de ballenas y lobos, y la extracción guanera. Sobre esto último, por ejemplo, diferentes anclajes ocurridos después de 1842 declararon aprovisionar a los barcos guaneros en la costa este 
patagónica o bien provenir de un establecimiento llamado Watchman's Cape, que se ha podido vincular con la extracción de guano regional (Allyn, 1879).

La circulación de navíos en la Patagonia no era unidireccional hacia las Malvinas, pero las fuentes muestran que estas islas mantenían un eje gravitacional en la economía local: un número mucho mayor declaró provenir de puntos de la costa continental o de sus islas adyacentes que dirigirse hacia ellos. Entre el continente, las islas adyacentes y el archipiélago malvinense las embarcaciones transportaban animales, sobre todo ovejas y caballos, $\mathrm{O}$ derivados de animales como cueros, pieles, aceite y huevos de pingüino, guano, plumas y lana. Distintos viajes declaraban restos de naufragios, dando cuenta las actividades regionales de raqueo. La importación de caballos provenía mayormente de Río Negro, Río Gallegos y San Julián: uno de los primeros proyectos que tuvo el gobierno inglés cuando ocupó las islas fue el de aparear sementales traídos de Gran Bretaña con yeguas patagónicas, en tanto se creía que el caballo de la Patagonia continental tenía una mejor resistencia y adaptabilidad al clima y al trabajo que los equinos que se encontraban en las Malvinas. ${ }^{12}$ Lo mismo se consideraba de las ovejas. ${ }^{13}$ La información recabada sobre la fauna regional y los sucesivos engranajes puestos en marcha para conectar los distintos puertos del mar patagónico ponen de manifiesto la disposición por parte de la administración malvinense de relacionarse con otros puntos cercanos para impulsar su economía. Los viajes que transportaron ovejas desde 1843 hasta 1870 se declararon sobre todo provenientes de Río Negro y Montevideo. También se listaron otros lugares como Patagonia, Buenos Aires y Gran Bretaña. Sobre fines de la década de 1890 comenzaron a transportarse ovejas desde Malvinas hacia Punta Arenas y Río Gallegos, y en menor medida este comercio involucró a Río Grande, Tierra del Fuego, Santa Cruz y Camarones en Chubut. A partir de 1898 los registros relativos al transporte de ovinos especifican ubicaciones del archipiélago con las que se generó este tráfico como Fox Bay, San Carlos y Hill Cove. En menor medida había intercambios de otros ítems como madera [Wood, lumber, posts], sal, papas o sundries [misceláneas, artículos pequeños]. Unos pocos viajes se dedicaron al transporte de pasajeros, hubo circulación de diferentes familias y misioneros entre Punta Arenas y el archipiélago, así como población indígena fueguina que era llevada a la misión protestante de la isla Keppel, que estaba situada en la parte occidental del archipiélago malvinero. Hay también un par de referencias a "Negroes" o "Niggers" en la columna de los cargamentos en el año 1859, lo que indica que los esclavos o las personas que lo había sido no eran considerados como pasajeros por las autoridades navales. Entre otros viajes aislados, algunos

\footnotetext{
${ }^{12}$ En el libro de Jiménez et al., 2018 también se menciona el transporte de caballos desde Carmen de Patagones por parte de los británicos.

${ }^{13}$ Jane Cameron National Archive. Miscellaneous Letters - Outward - B1. Carta al Government House por parte del gobernador Moody. 1 de julio de 1843. P. 186.
} 
se dedicaron al salvataje de las tripulaciones náufragas en la costa continental y sus islas aledañas.

La economía mundial, las rutas transoceánicas y las dinámicas extractivas fueron los factores que impulsaron el crecimiento inicial de la navegación en las islas Malvinas. Pero las múltiples relaciones con la costa sudamericana posibilitaron y fomentaron su desarrollo en cuanto a la economía interna: desde el empleo de gauchos como mano de obra, cuyas técnicas y cultura material fueron apropiadas y fomentadas para las tareas camperas en el archipiélago, hasta el comercio de caballos, ovejas, y madera, entre otros bienes. La historia del archipiélago malvinense está profundamente involucrada con la historia del continente, con el Río de la Plata, los puertos magallánicos y los patagónicos que se nutrieron de las islas, y viceversa.

Las conexiones de las Malvinas hilan una historia transnacional con eje en el mar patagónico. En su vértice geográfico se han unido, en la forma de viajes oceánicos, distintas regiones del mundo. Los registros portuarios han permitido una descripción de las conexiones navieras que dejan al descubierto las relaciones políticas, sociales y económicas. La importancia de la ubicación del archipiélago y sus recursos naturales posicionaron a las islas como un punto importante para distintas naciones, entre ellas Francia, Gran Bretaña, Estados Unidos, Alemania y Chile. El hecho de que Gran Bretaña constituyera la principal fuerza naval del mundo al momento de su ocupación de las Malvinas hizo posible el funcionamiento del archipiélago como punto de escala, como también las múltiples actividades económicas que impactaron en las rutas navieras que pasaban por el archipiélago (principalmente la industria del guano, la fiebre de oro en California y la explotación minera en Chile). El gobierno británico, luego de imponerse en las islas, tuvo los recursos para canalizar sus ventajas marítimas. Para 1914, la apertura del canal de Panamá terminó de marginar la situación del mar patagónico. Para entonces las nuevas tecnologías, los canales marítimos y ferroviarios ya habían hecho perder importancia al Cabo de Hornos. Fue unos años después, en 1917, cuando el gobierno argentino clausuró el faro de isla Observatorio, en vistas de la reducción del tráfico marítimo en el área.

Olivos, Buenos Aires, febrero de 2020

\section{Bibliografía}

Allyn, Gurdon E. (1879). The Old Sailor's Story, -or a short account of- The life, adventures and voyages of Capt. Gurdon L. Allyn, Including Three Trips Around the World. Written by himself, In the Seventi-ninth and Eightieth Years of his Age. 
Norwich, Connecticut: Gordon Wilcox. 1879. Disponible en: https://archive.org/details/cihm 14261/page/n5

Bascopé Julio, Joaquín (2018). En un área de tránsito polar: desde el establecimiento de líneas regulares de vapores por el estrecho de Magallanes (1872) hasta la apertura del canal de Panamá (1914). Villa Tehuelches: CoLibris.

Caviglia, Sergio Esteban (2015). Malvinas: Soberanía, Memoria y Justicia. Vol. II: Balleneros - Loberos - Misioneros. Siglos XVIII-XIX. Rawson: Ministerio de Educación de la Provincia de Chubut.

Centner, C. W. (1942). Great Britain and Chilean Mining 1830-1914. The Economic History Review, 12 (1/2): 76-82.

Dupont, Paul (ed.), (1849). Nouvelles annales de la marine et des colonies: revue mensuelle, Volúmenes 1-2. Paris: Dupont, P. 1849. P. 491.

Findlay, Alexander G. (1867). Sailing Directory for the Ethiopic Or South Atlantic Ocean, Including the Coasts of South America and Africa. Fifth Edition. London: Richard Holmes Laurie.

García, S y Podgorny, I. “L'exploitation de la faune marine dans l'Atlantique Sud : quelques idées pour une histoire globale de la zoologie et du commerce au XIXe siècle". En: Daniel Rojas (ed.) Amérique latine globale. Histoire connectée, globale et internationale, Paris: L'Harmattan, 2017, pp.17- 47.

Haller, Sofía y Vezub, Julio E. (2018). “Conexiones Interoceánicas de la costa patagónica en el siglo XIX: Antecedentes de historia marítima". Anuario IEHS, 33 (1): 15-38.

Howat, Jeremy N. T. (1989). Falkland Islands Mails: The Kosmos Years, 1880-1900. Londres: British Philatelic Trust.

Jiménez, Juan Francisco, Alioto, Sebastián Leandro, Villar, Daniel (2018). Malvinas Hombres, ganados y tecnología rural criolla (siglos XVIII y XIX). Bahía Blanca: Editorial de la Universidad Nacional del Sur. Ediuns.

Johnston, Alexander Keit (1853). Dictionary of Geography, Descriptive, Physical, Statistical, and Historical. Londres: Longman, Brown, Green, and Longmans.

Llorca-Jaña, M. (2016). Exportaciones chilenas de cobre a Gales durante el siglo XIX: su impacto en las economías chilena y galesa. Revista de Historia Social y de las Mentalidades, 21 (1): 27-62.

Lorenz, Federico (2011). “El malestar de Krímov. Malvinas, los estudios sobre la guerra y la historia reciente argentina". Estudios, 25: 47-75.

Lorenz, Federico (2013). "Reconstruir la historia". Le Monde diplomatique, 163: 10-11. 
Lorenz, Federico (2014). Todo lo que necesitás saber sobre Malvinas. Ciudad Autónoma de Buenos Aires: Paidós.

Martinic Beros, Mateo (1996). Inmigrantes malvineros en Magallanes. Magallania: Anales del Instituto de la Patagonia, Serie Ciencias Humanas, 24: 21-34.

Martinic Beros, Mateo, (2009). Relaciones y comercio entre Magallanes y las islas Falkland. Magallania, 37 (2): 5-21.

Mayorga, Marcelo Z. (2017). “Actividad lobera temprana en la Patagonia Oriental: caza de mamíferos marinos". RIVAR Vol. 4, N 11. Mayo 2017 pp 3151.

Minchinton, Walter (1985). "The Role of the British South Atlantic Islands in Sea-borne commerce in the nineteenth century". Actas del V Coloquio de Historia Canario-Americana, 4: 543-576.

Parker King, Phillip y Fitzroy, Robert (1860). The South America Pilot. Part II. From the Rio de la Plata to the Bay of Panama, including Magellan Strait, the Falkland, and Galapagos Islands. Fifth Edition. London: The Hydrographic Office, Admiralty.

Pierini, Milagros y Beecher, Pablo Gustavo (2012). “Malvinas y Santa Cruz: una relación histórica quebrada por una guerra", Malvinas en la universidad: concurso de ensayos Buenos Aires: Ministerio de Educación de la Nación.

Ross, Clark James (1847). A voyage of discovery and research in the southern and Antarctic regions, during the years 1839-43 by Captain Sir James Clark Ross, $R N$. with Plates Maps and Woodcuts in two volumes. Volumes I and II. London: John Murray, Albemarle Street.

Royle, Stephen A. (1985). “The Falkland Islands, 1833-1876: The Establishment of a Colony." The Geographical Journal, 151 (2): 204-2014.

Spruce Joan (1992). Corrals and Gauchos: Some of the People and Places involved in the Cattle Industry. Falkland Conservation Publication. Bangor: Peregrine Publishing. 